\title{
Cultura viva: entrevista com Paul Willis*
}

\author{
Por Roger Martínez
}

Introdução

Em fins dos anos de 1960, em um dos andares de um cinzento e alto edifício da Universidade de Birmingham, na Inglaterra, foi concebido o Centre for Contemporary Cultural Studies (CCCS), uma experiência que acabaria por revolucionar o estudo das culturas juvenis - e da cultura popular em geral. A tradição britânica do "Culture and Society", herdada de intelectuais da época, como Edward P. Thompson, Raymond Williams e o primeiro diretor do Centro, Richard Hoggart, seria a base de um coquetel de influências e formas de agir que mudou decisivamente o estudo das culturas juvenis: a partir de então elas não só foram estudadas em relação a suas produções culturais, mas se tentou ver nelas pistas para compreender as mudanças sociais e culturais das sociedades contemporâneas.

Paul Willis chegou ao Centro como estudante pouco depois de sua fundação, e hoje, quando o CCCS já não existe mais, continua sendo conhecido em todo o mundo como uma de suas vozes mais sugestivas. Atualmente é co-editor, com Loïc Wacquant, da revista Ethnography (Sage) e ocupa a cátedra de Etnografia Cultural e Social na Universidade de Keele, na Inglaterra. O livro que o tornou famoso, Learning to labour [Aprendendo a trabalhar] (1977), ilustra perfeitamente a sua contribuição aos estudos das culturas juvenis: a
*Entrevista publicada originalmente em Estudios de Juventud, 64/04. 
paixão pelo pensamento original, a aposta em uma aproximação etnográfica como alternativa aos trabalhos que se centram unicamente na análise textual e semiótica dos materiais da cultura popular, e a ambição teórica de pensar as relações culturais levando em conta tanto a importância das estruturas sociais e a autonomia da cultura como sua incorporação por parte dos indivíduos. Seu último livro, The Ethnographic imagination [Imaginação etnográfica] (2000), no qual estava trabalhando quando concedeu esta entrevista, constitui uma rubrica dessa atitude: um denso e elaborado posicionamento de autor, que defende uma voz própria em relação à corrente dominante dos atuais Estudos Culturais. Ao longo de sua obra, da qual fazem parte também os livros Profane culture [Cultura profana] (1978), The Youth Review [Revista de Juventude] (1988), Common culture [Cultura comum] (1990) e a versão não acadêmica deste último, Moving culture [Cultura em mudança] (1990), Willis sempre ofereceu uma voz lúcida que ajuda a interpretar a produção cultural dos jovens nos marcos das mudanças sociais contemporâneas. Seu ponto de vista sempre combina uma aguda elaboração teórica com um magnífico trabalho etnográfico, colocando exemplarmente em prática sua formulação precisa da boa pesquisa empírica como aquela em que o pesquisador "se deixa surpreender pela realidade” para alimentar sua elaboração teórica original.

Nesta entrevista, feita em sua casa em 1998, Willis reflete com paixão e profundidade sobre suas idéias e sobre os Estudos Culturais, respondendo às principais críticas feitas a sua obra e convidando-nos a pensar as culturas juvenis com respeito e interesse, a fim de entender melhor as mudanças sociais e culturais no mundo que nos rodeia, tanto em suas manifestações simbólicas como nos próprios corpos daqueles que as vivenciam.

O "Centro" de Birmingham

O senhor participou do Centre for Contemporary Cultural Studies (CCCS) de Birmingham quando ele era um foco de inovação. O que aqueles anos deixaram em sua memória?

De fato, cheguei ao Centro pouco depois do início de suas atividades. Richard Hoggart o havia inaugurado, creio que em 1967 ou 1968. Stuart Hall foi seu primeiro pesquisador (research fellow) e eu fui um dos primeiros estudantes, como todos no início, de pós-graduação. Era uma instituição muito pequena..., mas foi extremamente influente nos anos de 
1970 e 1980. A forma de trabalhar era muito diferente da das instituições tradicionais.

Quando cheguei, em 1969, Stuart [Hall] era editor da New Left Review, uma antiga revista marxista de esquerda que já existia havia muitos anos, e ele achava que uma instituição pequena como a de Birmingham poderia pôr em prática novas formas de trabalho, sobretudo formas coletivas de trabalho. Ali não havia uma relação estudante-professor no sentido tradicional. Tínhamos grupos de trabalho. Era um modelo que consistia em dirigir, utilizar e liberar os estudantes, e foi incrivelmente produtivo. A maioria dos livros feitos então não foram elaborados pelo professorado, mas por grupos coletivos, muitas vezes sem nem ao menos um professor.

\section{E o senhor havia acabado de estudar inglês em Cambridge!}

Sim, sobretudo do ponto de vista da minha experiência na extremamente tradicional Cambridge, foi para mim uma revolução participar do que parecia ser um contexto institucional horizontal, coletivo e progressista. Continuo acreditando que, ainda hoje, se tem que aprender muito com a maneira como trabalhávamos então, porque, por fim, acabamos retornando mais uma vez a uma forma institucional mais ortodoxa de trabalhar.

Por outro lado, o Centro tinha vários outros elementos muito estimulantes. Creio que ele se antecipou, em muito, em levar a sério a cultura popular, a experiência cotidiana, a música pop, o cinema e a televisão. E para mim isso também foi uma revelação. Até então, o posicionamento do mundo acadêmico era de que os artigos de consumo, o processo de conversão em artigo de consumo e a cultura popular eram lixo e estavam envenenando a instituição. Por isso tal posicionamento acreditava que se devia expulsar a merda e imunizar os estudantes contra sua influência. No Centro, ao contrário, partia-se do ponto de vista de que analisar seriamente esses novos fenômenos era extremamente interessante.

Era, portanto, um momento inebriante e emocionante. E também havia a sensação de compromisso político. Nesse momento acreditávamos estar comprometidos com o mundo real, acreditávamos que havia uma conexão direta entre os trabalhos acadêmicos e as implicações práticas e políticas. $\mathrm{O}$ primeiro trabalho de Stuart foi sobre meios de comunicação e políticas públicas (depois ele entrou em debates mais teóricos sobre codificação e decodificação), sobre a direção que os meios de comunicação deveriam tomar, sobretudo seus conteúdos culturais. 
1. Grupo de jovens aficcionados às motocicletas, muito tradicionais na década de 1960 (N. T.).
Também minha primeira pesquisa, quando era um estudante de doutorado e trabalhava dando aulas em cinco lugares diferentes para poder sobreviver, e obtive minha primeira ajuda, da Unesco. Queriam que eu analisasse os motards 1 para entender por que não iam ao teatro, às galerias de arte e à ópera. Eu tinha de tentar encontrar uma forma de fazê-los passar a freqüentar esses lugares. Repensei o assunto e disse que o problema não era que eles não tivessem cultura, mas que tinham a sua própria cultura. Então fiz um estudo etnográfico dos hippies e dos motards e disse à Unesco que uns e outros já possuíam formas simbólicas, e que talvez fosse o caso de entendêlas e apoiá-las, em vez de tentar atraí-los para a ópera como se fossem recipientes vazios, sem nada com o que começar.

Assim, tanto eu quanto o Centro tínhamos essa sensação de estar comprometidos e fazíamos qualquer tipo de trabalho que pudesse influenciar politicamente. Tudo isso era muito inebriante para mim. Tendo vindo de uma universidade tradicional, era emocionante e interessante.

O Centro também se caracterizou por combinar literatura com antropologia, com sociologia...

Sim. Era também muito interessante no que diz respeito às disciplinas e à metodologia. Naqueles tempos, no Centro (e esta é uma explicação muito resumida), havia uma mistura de literatura, sociologia e antropologia. De fato, o Centro, os Estudos Culturais britânicos, foi criado a partir do departamento de literatura inglesa, não do de sociologia ou do de antropologia. E Richard Hoggart, que foi quem o impulsionou, era professor de literatura inglesa.

Começamos então com literatura, e me parece que a idéia inicial de Richard Hoggart era utilizar as técnicas do criticismo literário, especialmente o que se chama de "leitura atenta" (close reading), ou seja, olhar uma poesia e entender como ela funciona: por que esta palavra e esta outra? Por que estes procedimentos e por que estas palavras nesta página? Como as palavras produzem significados? E utilizá-las não para analisar Shakespeare, mas Bob Dylan ou quem quer que fosse. $\mathrm{E}$ isso era um acréscimo muito interessante.

Também nos voltamos na direção da sociologia, da história e, sobretudo, do marxismo (Gramsci, Althusser). E também para o feminismo e as questôes de raça. Passei treze anos no Centro e me sentia como se a cada dois anos, mais ou menos, acontecesse uma nova revolução. Isso graças à 
estrutura coletiva à qual me referi, que funcionava mais de baixo para cima do que ao contrário. E nesse momento, além do mais, era um centro apenas de pós-graduação.

O humanismo inicial do projeto literário foi criticado pelo marxismo. Então, a partir de Althusser, se criticou o marxismo humanista. E depois o feminismo criticou Althusser. E, posteriormente, o anti-racismo criticou o feminismo e o marxismo. Em outras palavras, não era possível se estabelecer em uma perspectiva antes que outra revolução crítica apontasse um novo objetivo, e para meu próprio trabalho isso foi muito importante e emocionante.

\section{Mas o senhor sempre situa o seu trabalho mais próximo da etnografia do que da literatura ou da semiótica.}

Richard Hoggart queria manter as técnicas e as habilidades nas formas literárias do marxismo. Em um dos primeiros seminários, à tarde, eu tinha de fazer uma leitura detalhada de "The Tyger", o famoso poema de William Blake: "Tyger! Tyger! burning bright,/ In the forests of the night,/ What immortal hand or eye/ Could frame thy fearful symmetry?"2. Tinha de explicar as palavras que estavam na página, e depois, naquela mesma tarde, estive com os motards no local onde se reuniam, no centro da cidade, realizando o trabalho de pesquisa do que depois se tornaria Profane culture. Para mim, a vida era uma poesia. Em vez de analisar poemas, estava analisando por que os guidōes tinham forma de chifre, por que tanto aço cromado, por que eles se negavam a usar capacete. Eu estava usando as mesmas técnicas literárias de decodificação e análise, com respeito e atenção à forma simbólica. Aquelas mesmas técnicas que utilizamos quando lemos e analisamos poesia, eu as transferi para a vida real: a experiência era uma poesia, e para mim esse foi um direcionamento muito interessante.

Eu já estava meio cheio de Cambridge, que havia me confundido e me desconcertado um pouco, porque na verdade eu não tinha o capital cultural para fazer uma leitura detalhada de um poema. Mas no que se refere à cultura popular, sentia que sabia mais, e por isso me pareceu surpreendente o fato de transferir o respeito que se tem pela poesia: aquele respeito segundo o qual, se você não entende um poema, o problema não é dele, mas seu, $\mathrm{e}$ portanto você tem de trabalhar mais para conseguir entendê-lo.

Creio que esse direcionamento, essa transferência de respeito, foi efetivamente crucial: a questão não é se parece compreensível, anti-social ou sem
2. "Tigre, tigre, viva chama/ Que as florestas da noite inflama/ Que olho ou mão imortal podia/ Traçar-te a horrível simetria?" (tradução de José Paulo Paes) (N. T.). 
sentido, já que, ao dar por certo que aí há um sentido, então o problema é compreendê-lo. Isso permite que você abandone uma série de preconceitos e se concentre em entender, em vez de se dedicar a procurar razões para desvalorizá-lo, odiá-lo ou pensar que é um problema. Portanto, a transferência de respeito ("aqui existe um sentido") e a transferência de uma técnica ("como se produz o sentido simbolicamente") foram muito produtivas.

Acredito que Profane culture é um texto humanístico. E em muitos sentidos Learning to labour é uma luta, tanto dentro de mim como no papel, entre um humanismo etnográfico inicial (os jovens criando e sabendo o que estavam fazendo) e uma perspectiva marxista, que também aceitei, segundo a qual eles se encontravam em uma situação clara de exploração, por mais criativos que parecessem, que ficava evidenciada pelo fato de acabarem ou trabalhando em fábricas ou na fila do desemprego. Isso me colocou então um problema que ainda continua sendo o problema central, em muitos sentidos. Creio que a questão de como se reúne e se usa a criatividade implica a necessidade de técnicas humanísticas, etnográficas e literárias: como a criatividade se relaciona com as constriçôes estruturais, as condiçôes estruturais, a reprodução estrutural?

Portanto, a mesma história do Centro formou a mim e a minha pergunta. Creio que também foi importante o caminho por meio do qual chegamos na cultura, ou pelo menos como eu o vivi (não se esqueça de que esta éa "minha" história do Centro, e se você falar com qualquer outro estudante, ele contará a história dele). $\mathrm{O}$ fato de partir da perspectiva literária e o interesse pelas formas culturais foram automaticamente anti-reducionistas. E tomar emprestadas as técnicas da literatura impôs-nos imediatamente o respeito pela autonomia da cultura, no mesmo sentido pelo qual nunca questionei a autonomia da poesia.

Sobretudo naquele momento, isso abria uma rota claramente alternativa para compreender a consciência e a cultura, muito diferente das oferecidas pela sociologia ou pelo marxismo, que pareciam muito reducionistas, já que ou reduziam a cultura a alguma outra coisa ou se limitavam a vê-la como um problema ou uma patologia. $\mathrm{O}$ fato de partir do respeito pela cultura abriu uma via mais adequada, e depois, quando levamos a sociologia e o marxismo a sério, o fizemos à luz de um enorme respeito pela autonomia ou relativa autonomia da forma cultural. Minha própria formação consistiu, se se quiser, na força boa do humanismo transferida para as formas culturais vivas e, além disso, adicionando a tudo isso todas as questôes importantes em torno da estrutura, da constrição estrutural, da reprodução e, depois, 
do gênero e da raça.

Como o senhor compararia a sua abordagem com a de Stuart Hall e da principal corrente atual nos Estudos Culturais?

Quando Richard Hoggart deixou o Centro, um ano depois de minha chegada, e foi para a Unesco, em Paris, Stuart assumiu a direção. Foi sob o comando de Stuart que se formalizaram os temas e os textos marxistas teóricos e sociológicos mais radicais. Creio que Richard Hoggart e os primeiros humanistas se sentiram traídos pelo que veriam como uma invasão dos marxistas nos anos de 1970. Durante um período de dez anos, até Stuart ir para a Open University, em 1979, produziu-se a maioria das mudanças. Uma vez na Open University, Stuart dedicou-se a seus próprios interesses, sobretudo em relação ao pós-modernismo, ao discurso e à identidade, principalmente em relação à raça e à identidade, que eram somente alguns dos elementos originais dos Estudos Culturais britânicos. Não segui esse caminho, ainda que ele me interessasse. Ele escreveu sobre todas as divisões dentro dos Estudos Culturais (culturalistas, estruturalistas etc.). Seu último livro sobre o discurso e a identidade mostra de maneira clara qual é hoje, provavelmente, a corrente dominante dos Estudos Culturais anglo-saxãos: a da influência da linguagem no que poderíamos chamar de "paradigma lingüístico", na aproximação à cultura que considera que não há muito mais além de linguagem, no sentido de que outros sistemas de símbolos, como por exemplo os museus ou as fotografias, estão organizados como a linguagem. Ou seja, o signo não pode estar ligado ao referente de uma forma direta, umbilical, já que só assume um sentido a partir das exposições ou do sistema de símbolos. Além disso, há, sem dúvida, a conexão com a filosofia francesa de Derrida, o desconstrutivismo etc.

Vejo perfeitamente a lógica pela qual tudo isso passou a fazer parte dos Estudos Culturais, e por que houve esse direcionamento francês e lingüístico: a mesma autonomia da qual falei há pouco, que se formalizou em suas próprias teorias, enquanto eu ainda quero voltar a vincular a forma simbólica, seja ela linguagem seja qualquer outra coisa, à práxis humana. Acredito que os Estudos Culturais britânicos estão se esquecendo um pouco, progressivamente, da práxis humana. Sem dúvida alguma, todos esses debates e discussões são muito importantes, mas creio que há uma falta de referência a esses Estudos Culturais.

O livro que estou acabando de escrever agora [The Etnographic imagi- 
nation] tenta aprender com a teoria do discurso, sobretudo com o paradigma da linguagem. Sua característica fundamental é, obviamente, o significante flutuante: não há uma conexão necessária entre um significante e aquilo a que ele se refere. É uma posição antiessencialista.

Creio que todos os aspectos do meu trabalho anterior tinham um essencialismo humanístico no sentido de que estabelecia uma conexão demasiadamente simples entre a localização estrutural, as pessoas que atuavam e suas culturas. Evidentemente, de alguma maneira esses desenvolvimentos teóricos em torno do paradigma da linguagem, o significado flutuante, a não necessária correspondência entre a expressão cultural e a localização, não são nenhuma novidade para mim, porque já comecei com um forte senso da autonomia da manifestação cultural como arte estética, se se quiser chamar assim.

Na minha opinião, apesar de tudo, os desenvolvimentos mais interessantes tomarão o caminho de reunir o melhor das teorias do discurso e da identidade para ressituar tudo isso novamente em um sentido mais sociológico: a arte cotidiana, a prática cotidiana, consideradas também dentro de um contexto estrutural. Ou seja, para mim, a classe e a exploração ainda são importantes. O que acontece é que já não sabemos como a prática cultural e a consciência se conectam. Parece que existem alguns vazios consideráveis: autonomia, falta de conexôes. Não posso, apesar de tudo, acreditar que não haja conexôes. Ainda gostaria de voltar a uma unidade complexa, que incluísse numa mesma obra a cultura, a experiência, a identidade e a posição estrutural. Talvez seja pedir demais.

Sobre o bolo e os culturalistas, semióticos e estruturalistas

Essa é a diferença entre aquilo que se denominou de sua aproximação culturalista e a perspectiva mais semiótica de, por exemplo, Dick Hebdige.

Sim, há muitas formas de cortar o bolo, mas sempre considerei isso um pouco frustrante, porque nunca deixei de me interessar pelos símbolos. $\mathrm{O}$ problema é que, para mim, a semiótica saiu voando na direção de um mundo de símbolos, um mundo que poderia muito bem estar flutuando livremente.

Ao mesmo tempo, a outra grande divisão sobre a qual se falou é a do estruturalismo e do culturalismo. Supõe-se que o culturalismo seja a parte experimental e simbólica, enquanto o estruturalismo seria a parte do estru- 
turalismo althusseriano, mais forte, das formaçôes sociais. Mas não é verdade que eu tenha deixado de me interessar em algum momento pela estrutura. Muitas das posições estruturalistas, incluída a de Althusser, no fundo diziam muito pouco sobre a maneira como se relacionavam os diferentes níveis. Learning to labour é em seu conjunto um caminho para encarar essa questão: saber como se introduz a força de trabalho e, por outro lado, entender alguns dos mecanismos da autonomia, da independência e da complexidade da esfera cultural.

Em outras palavras, já sei que houve uma discussão muito longa, mas me considero um semiótico, culturalista e estruturalista.

\section{Mas é realmente possivel unir os diferentes niveis? Podemos unir a subjetividade a que o senhor se refere com a estrutura e a forma simbólica?}

Não acredito que se possa continuar utilizando o modelo marxista de infra-estrutura e superestrutura, ainda que Marx possa ser, ainda hoje, a melhor maneira de descrevê-lo pictoricamente, esquematicamente. Não creio que, apesar de tudo, nos diga algo sobre a relação entre esses elementos, já que está claro que há um nível material da cultura e um nível cultural do material. E as formas como esses níveis se relacionam são freqüentemente específicas dos casos originais. Se ainda por cima se acrescentam estruturas de subjetividade em relação ao gênero ou à raça, então o modelo se torna complicado demais para ser controlado. Assim simples. Por isso acredito que, de alguma maneira, precisamos ser mais modestos teoricamente.

Hoje em dia não sabemos onde a maioria dos jovens está, e portanto é um erro utilizar o velho modelo. Ao mesmo tempo, parece-me absurdo acreditar que esses jovens só vivam no discurso e só adquiram suas identidades por meio de diferenças nos signos, já que também têm de sobreviver, e a força de trabalho se reproduz no capital: eles continuam nas escolas, nas fábricas, nas ruas e em suas casas. Eles têm de negociar as transições para a vida adulta, e têm quantidades muito complexas de poder geracional enquanto estão empregados, em nível institucional e em relaçóes laterais que também são muito complexas. E tudo isso é situacional, material, específico, e não relações gerais de gênero ou relações gerais da base.

Precisamente por isso se torna dificil entender como é possivel que dentro dos Estudos Culturais não se tenha estudado se as diferenças culturais juvenis podem 
implicar diferentes tipos de transiçôes às relaçōes sociais de produção...

Sim.

Evidentemente, Learning to labour seria uma exceção, mas unicamente do ponto de vista etnográfico de um grupo específico de um tipo específico de jovens.

Learning to labour era um livro sobre a cultura da classe operária. Creio que é muito interessante porque, de alguma maneira, é pós-moderno, no sentido de dar voz aos colegas e não aceitar, por exemplo, as categorias marxistas. Ao mesmo tempo, se nos fixarmos no material etnográfico (e com freqüência as boas etnografias vêm antes das boas teorias), grande parte da identidade dos jovens do livro girava em torno do consumo. De fato, eles se distinguiam dos professores e dos conformistas por meio do uso de artigos de consumo culturais: fumando, vestindo, bebendo etc.

Portanto, ainda que seja um livro sobre a antiga cultura operária de produção, muitos dos mecanismos implicados não eram os dos sindicatos, da cooperação, da mutualidade e de tudo aquilo que historicamente tendemos a identificar como típico da classe trabalhadora. Sua identidade situava-se completamente no terreno da cultura dos artigos de consumo. Ainda que agora estejam desempregados e sejam pobres, não se vêem a si mesmos como trabalhadores que votam em um partido de trabalhadores, mas como consumidores que votam nos conservadores, ou no partido trabalhista de [Tony] Blair, que está mais à direita do que os conservadores estavam antes. Assim, alguma coisa muito profunda e importante mudou nas relações culturais e nessas formas culturais piramidais (estrutura, localização, experiência e atividade).

A ausência de meninas

Angela McRobbie criticou Learning to labour porque o senhor se concentrou em grupos de colegas e deixou de lado as meninas e os conformistas ou explorados.

Considero isso muito interessante. Sempre houve muita curiosidade em saber por que me concentrei em grupos de meninos e não nas meninas. Minha resposta é que um método etnográfico, para que seja bom e profundo, requer que se limite o objeto de estudo. Não o encarei como um enfoque sexista, antifeminista ou antigênero, porque creio que fui um dos primeiros 
a indicar a importância do gênero na formação dos jovens da classe operária.

Acredito também que, uma vez mais, é isso que falta a muitas análises semióticas, por mais sofisticadas que sejam: extrair o sentido etnográfico da experiência cotidiana, da maneira de as diferentes ordens e categorias simbólicas se combinarem mutuamente. Assim, atendo-me muito de perto a um exemplo, queria entender como as diferenças de gênero podiam relacionar-se com outras diferenças, como a classe operária e a classe média. E, evidentemente - isso é muito importante -, o trabalho intelectual e o trabalho manual.

Neste caso, interessavam-me as formas pelas quais a masculinidade tinha se associado ao "manualismo" e ao trabalho manual, resultando em um descrédito das posições intelectuais. As categorias marxistas nunca foram capazes de explicar por si mesmas esse descrédito, já que o trabalho intelectual e as funções intelectuais são superiores e mais bem recompensadas. Para mim, essa continua sendo uma questão fundamental, e também entender como o restante das questôes (como a dos negros e dos brancos, entre elas), em casos específicos, e com exemplos em profundidade, se relaciona com a prática, se relaciona com a subjetividade e se relaciona com a questão da reprodução. Como, definitivamente, eles vivem e aceitam seu destino como trabalhadores homens negros e brancos.

Ainda acredito, portanto, que, para poder lidar com essas questôes, seja necessário fixar-se nelas muito de perto. Nesse sentido, a reclamação feminista segundo a qual eu havia excluído as jovens não se justifica. Creio que mais do que se fixar no objeto empírico, a lição que se tem de aprender (e depois aplicar às mulheres e aos grupos negros) de Learning to Labour, e isso muitas feministas não viram, é sua abertura teórica e o interesse que demonstra pela forma como o gênero se combinava com outras categorias. A crítica feminista é uma crítica empiricista a um estudo empírico, que consiste em dizer "Onde estão as meninas?".

Sem dúvida que teria sido melhor incluir as jovens e outros setores de classe, mas, a não ser que se compreenda um segmento com certa profundidade, nunca se poderá obter a matéria-prima para aplicar a abertura teórica à raça, ao gênero e a outras categorias. Entendendo por que aqueles garotos aceitavam aquele caminho (por que o grupo mais baixo aceita sua sorte?) torna-se mais fácil entender por que outros grupos se reproduzem: porque sempre podem encontrar alguém inferior quanto ao status ou à ordem econômica. O mais difícil é descobrir, ou entender, ao mesmo tempo que se transmite respeito humano e dignidade, por que aqueles em uma situação 
inferior aceitam sua sorte. Assim, sempre fico perplexo quando se critica esse aspecto de Learning to labour.

\section{As rodas do consumo e as hierarquias internas nas culturas juvenis}

O Centro estudou preferencialmente as culturas ou as subculturas ditas "espetaculares" e masculinas. Cada vez mais, ao contrário, é habitual estudar as mulheres e a juventude "normal". Qual é sua posição com relação a essa tensão entre "normalidade" e "espetacularidade"? Até que ponto é interessante relacionar isso com as hierarquias internas da cultura juvenil, como fez, por exemplo, Sarah Thornton?

Creio que não exista uma solução para sua pergunta, que seria: Qual é a função, o significado e a importância, hoje em dia, das diferenciações hierárquicas dentro da cultura juvenil? Não creio que nada disso esteja claro. Quero mais exemplos etnográficos empíricos sobre as relações de classe, preciso ver os resultados, e também quero uma maior compreensão fenomenológica e semiótica do funcionamento da cultura.

É verdade que existem algumas idéias genéricas que eu gostaria de levantar. Uma delas é que a época da subcultura espetacular foi uma expressão inocente que seguramente já chegou ao fim. Foi um momento inicial no qual se fazia uma utilização naïf dos artigos de consumo, como os grupos de jovens [de Learning to labour] que fumavam e bebiam há vinte anos, para mostrar que eram superiores. Creio que os estilos formados a partir de artigos de consumo foram, eles mesmos, convertidos em artigos de consumo, que por sua vez criam um novo estilo, de maneira que não existe uma posição de classe autêntica, baseada em uma relação externa aos artigos de consumo e que possa utilizar esses artigos de consumo para uma expressão contrária ao capital, contrária à escola, ou algo parecido.

Mas já estamos há algum tempo nesse processo de conversão em artigo de consumo e, na minha opinião, dificilmente poderemos descrever uma cultura como autêntica, como se tivesse relações e experiências sociais externas ao mercado e utilizasse o mercado em um sentido criativo. É isso em parte o que aconteceu com o pós-modernismo e, em parte, aquilo com o que todos nós estamos brigando para tentar encontrar um caminho. Temos um pé no terreno da exploração, do cinismo e da conversão em artigo de consumo. Os significados que nos são importantes não são proporcionados pelos sindicatos com freqüência nem mesmo pelas escolas -, mas por aqueles que estão fazen- 
do negócio conosco. Recolhem nossas próprias idéias e depois as devolvem, vendendo-as de novo a nós mesmos, de forma que estamos continuamente mudando os signos. Essa é uma questão importantíssima para mim, a da etnografia relacionada com as formas dos artigos de consumo e as relações associadas aos artigos de consumo.

Creio que não só os punks, os mods ${ }^{3}$ ou as elites espetaculares, ou os semióticos universitários, mas todos nós somos lançados e temos de viver em um sistema de desconstrução prática: não acreditamos na televisão porque dizemos que só serve à publicidade; não acreditamos em nada do que nos dizem porque sabemos que estão tentando nos vender algo; não acreditamos no que nos diz o professor na escola porque sabemos que, a fim de conquistar a nossa atenção, ele tem de se vender como se fosse um artigo de consumo.

A maioria dos atuais filmes de Hollywood mostra uma visão radical no sentido de "não acredite nos meios de comunicação", "não acredite nos políticos", "não acredite na justiça" etc.

Esse é outro exemplo do que estou falando: os círculos contínuos de conversão em artigo de consumo chegam ao ponto de converter a anticomercialização em artigo de consumo, de maneira que tudo acaba entrando nesse círculo. Isso nos obrigou a desenvolver habilidades consideráveis de desconstrução e diferenciação semiótica. Talvez você não saiba exatamente como os anúncios o afetam, mas você não acredita neles e ponto, o que nos leva a uma situação difícil em termos de desenvolvimento social e formas de relação social mais responsáveis: "Não entendo exatamente o que você está me dizendo, mas sei que é uma merda". E isso se aplica aos chefes das empresas e aos sindicatos, aos dirigentes políticos, aos professores e diretores de escola etc. E a questão é que em alguns desses casos as pessoas estão tentando de forma sincera colaborar com o nosso desenvolvimento.

Acredito que isso torne muito difícil falar em qualquer tipo de cultura autêntica que seja melhor que outra, como se houvesse um terreno não comercializado a partir do qual se podem julgar todas essas coisas. Portanto, em muitos sentidos, os dias das subculturas espetaculares chegaram ao fim. Pode-se argumentar que, inclusive se você é uma pessoa normal assistindo televisão, em grande parte a qualidade de sua relação com as imagens, os meios e as mensagens é similar ao trabalho do subculturalismo espetacular há trinta anos.

Quero ter um conhecimento mais etnográfico do que isso significa. Não
3. De "modernistas": uma tribo urbana de jovens de origem trabalhadora da Inglaterra, na década de 1960 (N. T.). 
acredito em equações simples. É uma questão etnográfica importante. De alguma maneira, qualquer grupo se encontra no meio de uma confluência complexa de elementos, na qual tem de tentar encontrar sua posição. E o faz utilizando os materiais proporcionados pelos artigos de consumo, evidentemente, mas também pelo gênero, pela raça e por alguns aspectos da classe. É assim que cada um descobre por que está onde está. E os jovens se confrontam com todo tipo de redes complexas de poder e posição: eles têm de trabalhar e se preocupam com a transição à esfera econômica, eles têm de encontrar caminhos subconscientes informais para entender a sexualidade, o gênero, a raça etc. Há alguns recursos culturais usados para saber quem você é. Uma identidade consiste, seguramente, em colocar isso em um mapa, no qual estão os outros, os outros que não são tão diferentes, e você mesmo.

\section{Mas esse mapa é um mapa hierárquico, não é?}

Sim, mas está estruturado de uma maneira que não se encaixa na noção de hierarquia subcultural que Sarah Thornton utiliza. Não é só uma questão de ser mais underground ou de seguir a "corrente majoritária", mas de querer ver como essa noção de capital subcultural de Thornton se relaciona com a raça, com a classe, com o gênero ou com as questôes de hierarquia geracional. Por isso digo que é uma pergunta etnográfica.

Mas alguns jovens tentam, em parte, diferenciar-se da "maioria", da "massa", e portanto reproduzem mecanismos elitistas.

Se o que eles querem é diferenciar-se, por que não vão a museus, a galerias de arte e a peças de Shakespeare? A elite seria uma maneira de diferenciar-se. Se o problema é demonstrar que são superiores, por que não freqüentar instituiçôes que dizem que você é superior se gostar da arte ocidental clássica? Ao não utilizar a arte tradicional, isso significa que há uma resistência. Estão resistindo à Arte e ao mesmo tempo à cultura popular.

E essa vontade de distinguir-se da "corrente majoritária", da cultura mais comercial e "normal", podia ser anticapitalista. Ainda que seja evidente que discutir as motivações é extremamente complicado. Do meu ponto de vista, algumas causas reais podiam não estar na consciência, mas sim mediadas pela forma cultural (que dará melhores recompensas e proporcionará significados, alguns deles não verbais).

A forma estrutural do elitismo poderia influir em um certo freio do ciclo 
pós-moderno de conversão em artigo de consumo, de maneira que não fosse questão de ser melhor em um sentido elitista, no sentido de eu ser considerado melhor porque estudei em Cambridge e sei literatura, mas de ser melhor no sentido mais autêntico: o mercado afetou-o menos e você tem uma posição quanto às relações sociais e ao gosto que não é comercial. Dizendo claramente: nenhum mau caráter está fazendo negócio com você.

Acredito que, sobretudo nas primeiras subculturas britânicas, havia uma autenticidade, uma posição externa aos artigos de consumo, e se utilizavam esses artigos para indicar essa posição. Mas, é claro, meu argumento é que hoje em dia estamos totalmente no terreno do artigo de consumo e que já não é possível ser autêntico. De maneira que o que se chama de elitismo pode ser tranqüilamente uma tentativa de manter-se fora da comercialização. E isso é, evidentemente, impossível.

Estamos diante de um novo elitismo situado no terreno dos artigos de consumo e não necessariamente no sentido da distinção como é dada por Bourdieu, de ser melhor ou superior. O antigo elitismo da cultura oficial tenta manter-se fora da comercialização, tenta dizer que não lhe estão dando materiais significativos para que você faça negócio, mas para fazer de você uma pessoa melhor. A razão pela qual estão fracassando e estão em crise é porque os artigos de consumo são muito mais sexys e proporcionam um contato muito mais sensual com os consumidores. Uma questão interessante é que, enquanto esse novo elitismo dentro da cultura popular também seleciona alguns elementos da cultura oficial, ainda que isso precise ser analisado, a antiga elite continua limitando-se unicamente às suas galerias de arte.

Essa questão da hierarquização dentro da cultura comum e de se ela reproduz homologamente ou não a Arte como hierarquia oficial, como arte oficial, é muito interessante. Minha resistência está ligada a possíveis formas de considerar o argumento. Ou seja, se isso significa que o elitismo é aceitável, e deixamos que todo o elitismo subcultural se concentre, então em vinte anos teremos outra cultura oficial, com outro Shakespeare que agradará a toda a população educada. E em termos econômicos, sociais e culturais essa população educada será diferente dos "idiotas" que gostam das Spice Girls ou do Abba. Esse tipo de idéia me preocupa, devido às inaceitáveis e lamentáveis conseqüências sociais do modelo elitista que equipara Alta Cultura e Cultura Oficial.

Minha posição é que necessitamos de uma nova noção de elite. Dessa maneira poderiam ser resgatadas as relações de capital do processo de co- 
mercialização para a resistência, em vez de para aquilo que o elitismo sempre nos sugere: que, se existe um grupo de elite, seus membros se consideram superiores, o que implica andar de mãos dadas com o resto dos signos de dominação (que eles serão os chefes, os professores etc. do futuro).

\section{Estudos culturais, trabalho acadêmico e compromisso politico}

Gostaria de falar agora da questão do compromisso ou da implicação com o mundo real. Como se vivia, no Centro, esse compromisso com a realidade social e política da qual o senhor falou no início da entrevista?

$\mathrm{Na}$ constituição dos Estudos Culturais no Centro, o fato de dirigir o olhar para a música popular, para as subculturas e para os meios de comunicação implicou um compromisso imediato com a realidade do momento. Tínhamos a sensação de que se podia mudar o mundo e de que, portanto, podíamos estudar a instituição em que trabalhávamos e as relações externas em parte com essa intenção. Ainda que não estivesse muito claro como isso devia ser feito, eu tinha a sensação de que meu trabalho era comprometido e de que existia a possibilidade de ele ser lido fora da instituição. E talvez também pelas mesmas pessoas que eu havia estudado.

Do meu ponto de vista, os especialistas em criticismo cultural da linha mais teórica, textual e semiótica dos Estudos Culturais de alguma maneira repetiram o distanciamento próprio das tradiçôes da crítica cultural e da Arte com maiúscula com relação aos quais pensávamos estar nos diferenciando radicalmente. Estamos repetindo um elitismo dentro do mundo acadêmico. $\mathrm{O}$ mundo acadêmico está se convertendo em uma grande torre que já não faz parte da realidade.

Qual o seu balanço pessoal em relação à conexão entre a esfera acadêmica e a prática politica e social?

Essa é uma questão que sempre me preocupou. De fato, passei quase dez anos fora do mundo acadêmico trabalhando para o partido trabalhista, analisando o terrível impacto do desemprego juvenil. Trabalhei ali elaborando o informe The Youth Review, em que analisei as experiências culturais dos jovens. Eu sugeria que a posição do governo local em relação ao desemprego tinha de mudar, porque já não se podia continuar pensando que todo o mundo iria encontrar um trabalho mais cedo ou mais 
tarde. No início dos anos de 1980, havia enormes grupos de jovens que não conseguiriam um trabalho em toda a sua vida, que sempre teriam uma experiência muito difícil em relação ao trabalho: falta de perspectivas, desemprego, retornos a trabalhos temporários esporádicos etc.

Revisei todos aqueles aspectos do governo local relacionados com o que denominei "nova condição social do desemprego", que especialmente para a classe trabalhadora consistia em transiçôes truncadas ou quebradas: não conseguir o poder que o salário dá, para fazer o resto das transições para a vida adulta (transição de ir morar por conta própria, de ser consumidor, de ter relaçôes laborais, de relacionar-se com um sindicato etc.). Tudo isso depende de a pessoa ter um trabalho. E ainda que essa seja uma situação temporária - ou pelo menos eu gostaria de pensar que é - que se está prolongando continuamente, continuamos oferecendo, aparentemente, as mesmas transições para o futuro. Para muitos, ao contrário, essa transição não se completará nunca.

Com The Youth Review eu estava realizando uma tentativa muito precoce de uma análise comprometida com a realidade. Foi uma experiência que eu esperava que retornasse a alguns daqueles mesmos grupos, no sentido de expressar as frustrações de sua situação, e que por sua vez também colocasse à administração local a importância de políticas dirigidas à condição social, às transiçôes truncadas (em vez de acreditar que as antigas transições e a rede de bem-estar dos programas de formação individualizados poderiam representar muito para os jovens que estavam nessa situação). Também se criou o fórum juvenil eleito democraticamente, que é uma representação juvenil na comunidade, que levanta questôes de calibre muito diverso. Existiam também os planos de residência específicos para os jovens. O problema é que os recursos à disposição do governo local estavam congelados ou até mesmo se reduzindo. Tudo isso foi uma tentativa muito precoce de apresentar a questão das transições alternativas em relação à maneira como os serviços estatais, a prefeitura e a burocracia local deveriam tentar responder às questóes reais, ou às questóes vividas por aqueles que estavam experimentando as transições truncadas (em vez de operar com um modelo vinte anos defasado em termos da experiência real dos próprios jovens).

A política local em Wolverhampton ${ }^{4}$ estava baseada na perspectiva $\mathrm{da}$ juventude e pelo menos discutia e recodificava, e - se se quiser dizer desta maneira - era mais sociológica, estava baseada na experiência cultural e na experiência real daqueles que viviam essas transições. Essa tentativa de influir nas políticas concretas e de pôr a análise à disposição daqueles aos 
4. Foi como participante no conselho municipal dessa cidade que Paul Willis realizou seu estudo sobre o desemprego entre os jovens (N. T.). quais ela afetava teve uma importância muito grande para meu próprio trabalho e para a minha carreira. E agora voltei ao mundo acadêmico...

O livro Common culture e sua versão reduzida e orientada para as implicaçôes práticas, Moving culture, também tiveram uma influência na realidade social, não é?

A Fundação Gulbenkian, para a qual esse estudo foi feito, oferece financiamento na área do bem-estar social, da educação e da cultura. Tenta ajudar o desenvolvimento cultural, social e educativo dos jovens. Antes de Common culture, as ajudas econômicas, em termos gerais, acabavam indo para os adultos. Eles acreditavam que sabiam o que o jovem queria. Depois de Common culture isso mudou. Foi permitido que grupos auto-organizados de jovens recebessem subvençóes.

Eu participei do Painel Consultivo do Arts Council da Inglaterra, que há pouco tempo mudou as regras da subvenção das artes com a intenção de orientá-la mais para os jovens e a cultura popular. E, ainda que não possa nem queira reivindicar minha influência, o Novo Trabalhismo está se mostrando muito mais amigável com a cultura popular, ou pelo menos com a sua produção, e está limitando as subvençōes à cultura oficial. A visão deles não é exatamente igual à minha, mas caminha em uma direção similar. Eles tentam vincular o partido a uma imagem nova e moderna da Grã-Bretanha como marca juvenil, ainda que isso talvez já comece a decair. Acredito que meu mérito foi ter sido capaz de articular aspectos de um novo estado de ânimo, de uma nova sensibilidade, de maneira muito precoce. Mas não comecei nada e não estou completamente de acordo com tudo o que agora se considera fantástico e estimulante.

Creio que em muitos sentidos é uma desgraça que, quanto à maneira de o Estado de Bem-Estar se relacionar com a população e suas circunstâncias, os sociólogos e aqueles que pertencem à corrente dos Estudos Culturais não tenham jogado um papel mais importante na hora de fazer a conexão com a experiência real, as necessidades reais, nas atuais revisões do Estado. E acho que isso seja assim porque grande parte do Estado é inflexível, burocrática e nada sensível às mudanças. Grande parte da política cultural está fundamentada na cultura oficial, enquanto a maioria dos jovens caminha em uma direção muito diferente.

Defendi em The Youth Review que em muitos sentidos os jovens tentam encontrar suas próprias transições alternativas e que essas transições alterna- 
tivas são encaradas, do ponto de vista dos agentes estatais, como patologias, como problemas, como desobediência às normas etc. O Estado está se convertendo em inimigo, não em amigo, porque não responde às questões que todos os jovens vivem ou experimentam. Mas são os jovens que estão nessa situação, e não podem sair dela e escrever um livro sobre a semiótica do estilo. Eles não podem de um momento para o outro escrever críticas marxistas sobre as mudanças da globalização internacional.

Ao mesmo tempo, pesquisa não deveria ser o mesmo que política, porque o trabalho acadêmico não é política. Mas acredito, sim, que o trabalho acadêmico possa ajudar a guiar a política, e possa (e esse é o elemento fundamental de minha posição em relação à política e ao trabalho cultural) tentar ajudar aqueles que estão implicados nela: os jovens e as jovens que estão fazendo história. Possa tentar fazer com que a conduta de alguns deles lhes pareça mais transparente, de maneira que tornem a mediação cultural e as escolhas possíveis mais legíveis. E possibilite também que o financiamento público, a nova política de financiamento da identidade cultural, seja produto de uma relação mais dialética e reflexiva.

\section{A qualidade e o populismo cultural}

Em Common culture, o senhor enfatiza a criatividade implícita no consumo cultural dos meios de comunicação, da roupa e inclusive da cerveja. Só no apêndice trata da questão do "valor", da "qualidade", que não joga nenhum papel em seus argumentos sobre a criatividade cultural. Por essa razão o acusaram de "populista cultural", ainda que, em seu livro, o senhor esclareça que se limita a concentrar-se na relação que o sujeito estabelece como texto, em vez de concentrar-se, comoémais habitual, no texto mesmo. Oque osenhor acha dessa crítica?

Da mesma maneira que as divisões entre culturalismo e estruturalismo, ou entre culturalismo e análise semiótica, isso tem mais de briga acadêmica interna do que de representação de posiçôes que correspondam à realidade ou à experiência de vida real. E da mesma maneira que sempre me opus à etiqueta de culturalista, também me oponho à de populista cultural.

Para mim é muito importante o fato de que com o direcionamento semiótico tenha havido uma perda de corpo, uma perda de sensualidade. $\mathrm{O}$ paradigma lingüístico é muito útil para o sistema lingüístico, mas não creio que seja tão útil para os sistemas de expressão corporal.

Além do mais, não disse que o comércio seja maravilhoso. O que faço é, 
simplesmente, aceitar que a maior parte da experiência se baseia em significados comercializados e continuamente reciclados que circulam. Meu problema com os estudos da cultura popular é que sempre estão falando dos textos e das formas, em vez de centrar-se na experiência cotidiana e vivida.

Há uma clara distinção, em minha própria terminologia, entre cultura popular e cultura comum (common culture). A cultura popular faz referência a textos e objetos, aos lucros e ao mercado, enquanto a cultura comum faz referência à utilização disso e aos significados culturais comuns, que também incluem os significados tradicionais, os significados interpessoais e, se se quiser, o que sobrou da cultura original de classe.

Quando você utiliza um elemento da cultura popular, obtém satisfação sensual e passa a fazer parte da cultura comum. Há uma distinção entre os objetos da cultura popular e sua utilização, a prática. Se você fosse um antropólogo que vem de Marte para ver como vivem as pessoas na Espanha, evidentemente perceberia que elas assistem televisão! Evidentemente perceberia que compram roupa! Se você fosse um antropólogo, teria de levar a sério o processo de conversão em artigo de consumo e também a cultura popular.

Há uma diferença muito grande entre isso e dizer que estamos no melhor dos mundos possíveis. Só me limito a dizer como as pessoas vivem e quais são os materiais que utilizam. E esses materiais são os da cultura popular. Do meu ponto de vista, a questão não é tanto se a cultura popular é boa ou má, já que, simplesmente, "é o que existe". Isso nos obriga a entendê-la melhor, e entendê-la em termos das formas de utilização e possibilidades de mudança abertas, não em termos das perguntas que, no fundo, são próprias da cultura oficial: é bom ou mau? É tão bom quanto Shakespeare?

A comercialização, o ciclo de conversão em artigo de consumo e minhas outras perguntas deslocam, portanto, a questão da quantidade. Há uma grande diferença entre isso e dizer que não há questôes sobre a qualidade, e, de fato, tentei abordá-las em Common culture.

Claro que eu sei que a cultura popular foi criada por capitalistas cínicos e manipuladores com o objetivo único de fazer negócio. Mas... o que isso tem de brilhante? É claro que sei! O problema é que as pessoas antipopulistas parecem querer voltar a um momento anterior à existência dos artigos de consumo, em que havia campos da experiência independentes dos artigos de consumo, campos que são uma base formal para criticar a comercialização. Isso é, em parte, o que eu disse sobre o início dos Estudos Culturais 
e dos estudos subculturais: acredito que já não se possa encontrar uma base autêntica onde se situar e dizer que isso seja real, que seja uma expressão de classe, que se esteja utilizando os artigos de consumo para se ser anticapitalista.

De alguma maneira, a posição antipopulista substituiu a posição estruturalista. As críticas ao chamado populismo são muito similares às críticas dos estruturalistas aos culturalistas. E se a crítica é a de que os artigos existem para se fazer negócio, minha resposta é: "Muito bem, isso eu já sei, mas me mostre como (com exemplos etnográficos empíricos) isso produz efeitos ideológicos indesejáveis". Não há dúvida alguma de que o artigo de consumo existe para se fazer negócio e que os artigos que pretendem oferecer um significado e uma receptividade comunitária não podem fazer isso porque são fetichistas, porque são, todos eles, artigos de consumo. Meu argumento é de que, hoje em dia, os consumidores também sabem disso e que, assim, todos nós nos deslocamos para um estágio de desconstrução prática, cinismo prático, descrédito prático generalizado.

Em conseqüência, se é essa a acusação contra os artigos de consumo, estou de acordo com ela. Essa é uma questão geral, mas as antigas perguntas continuam intactas: $\mathrm{O}$ que as pessoas reais fazem com os artigos de consumo? Como encontrar a autenticidade real na cadeia contínua de inautenticidade? Como esses elementos criativos funcionam em um contexto de obtenção de lucros? Como esses elementos se relacionam com algumas questóes realmente antigas? Como se entende o trabalho? Como se entende o não ter trabalho? Como tudo isso mudou o sentido do trabalho, quando, pela proliferação de significados, ofertas e promessas de satisfação promíscuas, o trabalho se converteu em uma fonte de identidade menos importante?

Essas são as razões pelas quais não podemos ignorar o processo de comercialização. É necessário compreender, pelo respeito aos exemplos empíricos, como funciona a cultura dos artigos de consumo. Para mim, essa é uma pergunta etnográfica, antropológica e de cultura corrente. Para mim não se trata de sentar-se em uma torre de marfim criticando a cultura popular e seu tempo.
Texto recebido e aprovado em 31/5/2005.

Roger Martínez é sociólogo, foi professor associado do Departamento de Sociologia da Universidade Autônoma de Barcelona (2002-2003) e coordena atualmente a área de Sociologia e Ciência Política dos Estudos de Humanidades e Filologia da Universidade Aberta da Catalunha. Email: rms@menta.net 